\title{
Numerical Investigation on Mixing Characteristics in Quenching Zone of Annular RQL Combustors
}

\author{
JI Yongbin ${ }^{1}$, MAO Ronghai ${ }^{2, a}$, YUAN Yongwen ${ }^{1}$, Shen Suhua ${ }^{2}$ and Ge Bing ${ }^{1}$ \\ ${ }^{1}$ School of Mechanical and Power Engineering, Shanghai Jiaotong University, China \\ ${ }^{2}$ AVIC Commercial Aircraft Engine Co. LTD., China \\ a maoronghai@acae.com.cn
}

Keywords: RQL; mixing characteristics; momentum flux ratio; mixing uniformity .

\begin{abstract}
RQL (Rich burn-Quench-Lean burn) combustion technology is one of the most promising ways to control NOx emissions for gas turbines, and it calls for an extremely quick and effective quenching process to realize. This study focuses on the influencing factors of the mixing characteristics including the quenching jet as well as mainstream flow velocity and the configuration of the quenching unit through numerical simulation. Especially, their effects on the mixing uniformity are discussed. The results show that, mixing performance is mainly determined by the momentum flux ratio of the quenching flow to mainstream flow, more momentum flux the quenching air gets, deeper will the jet arrives into the mainstream. The mixing uniformity is better for higher quenching jet velocity or lower mainstream velocity cases. Besides, slots can provide more uniform mixing than the simple round holes.
\end{abstract}

\section{Introduction}

Emission standard for civil aviation is more and more stringent nowadays, which in the other hand propels the development of low emission civil-aero engines. In this context, concept of the RQL combustor was first proposed in 1980 as an effective method to cut down the NOx emission for gas turbines ${ }^{[1]}$. After that, NASA adopted RQL as the combustion mode for next generation of civil-aero engine with low NOx emission in 1990s ${ }^{[2]}$. From its birth, quite a great amount of researches focused on the mechanism and influencing factors of mixing in the RQL combustor quenching zone. This is due to the key role of the quenching zone, which connects the rich-burn zone and lean-burn zone and so requires quick and highly effective mixing. Oechsle ${ }^{[3]}$ compared the mixing results represented by the temperature distribution between non-reactive and reactive cases, and they found that there was no big difference, which meant more quick non-reactive mixing results could be obtained to simulate the situation instead of reactive cases. The effect of quenching holes on mixing was investigated by Samuelsen ${ }^{[4-5]}$, who conducted experiments in a cylindrical combustor with the momentum flux and mass flow rate keeping constant. Their results showed that the penetration depth was a function of the quenching holes numbers, and when it reached 14 , best mixing came out. Zhu ${ }^{[6-7]}$ focused on the research on radial quenching jet into the crossflow in a cylindrical combustor. The concluded that the momentum flux was the most important parameter to influence mixing characteristics, and there existed a balance between mixing effect and pressure loss. Besides, they investigated the effect of swirling flow on the mixing performance and found swirling flow has little impact on the mixing. Blomeyer ${ }^{[8]}$ presented a study concerning the effect of flow parameters, the configuration of quenching holes as well as the duct (combustor) length on the mixing performance under the non-reactive cases. They pointed out that the Reynolds number and turbulence level of mainstream had little effect, while the swirling characteristic weighed much. Computational simulations were also carried out to supplement experiments for its convenience and lower cost. Gregory ${ }^{[9]}$ examined the mixing performance of the combination of quenching jets and mainstream with different momentum flux in chemical reactive as well as non-reactive circumstance through coding and simulating the mixing process in the quenching zone. Talpalllkar ${ }^{[10]}$ studied the effect of quenching 
zone area on the mixing performance using CFD commercial software and disclosed that the decrease of the quenching zone area wouldn't enhance mixing.

However, work on the mixing characteristics for RQL combustor is still few, let alone the mixing performance investigation in annular RQL combustor. The objective of this work is to reveal the mixing characteristics especially mixing uniformity in the quenching zone of an annular RQL combustor through CFD simulation. The effect of the mainstream as well as quenching jets flow velocity and the configuration of the quenching unit are discussed.

\section{Numerical Setup}

\subsection{Combustor Geometry}

The investigated combustor is a multi-nozzle (20) annular RQL chamber. The simulated scaled-up model is simplified into a $1 / 20$ sector of the chamber with only one nozzle. The fuel is injected through an axial swirler, as shown in Fig 1 , which has seven $45^{\circ}$ straight blades. The inner and outer diameters of the swirler are $34 \mathrm{~mm}$ and $70 \mathrm{~m}$, respectively, and its length is $29 \mathrm{~mm}$.

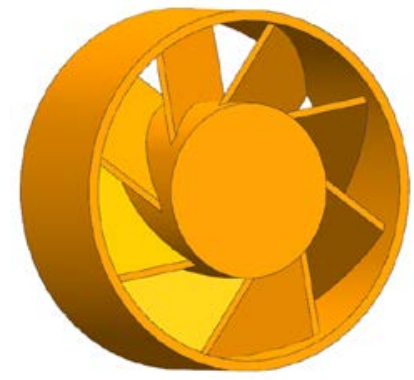

Fig 1 Axial swirler of RQL combustor

Besides, the combustor chamber is $237 \mathrm{~mm}$ in length, with the $388 \mathrm{~mm}$ inner diameter and $604 \mathrm{~mm}$ outer liner diameter. To compare different quenching unit configurations effect, except round holes, rectangle slots with $45^{\circ}$ deflection angle from the stream-wise are also considered, what should be emphasized is that all quenching units need keep the same air flow area.And, centers of both holes and slots are located $125 \mathrm{~mm}$ away from the outlet plane of the swirlers, as shown in Fig.2.

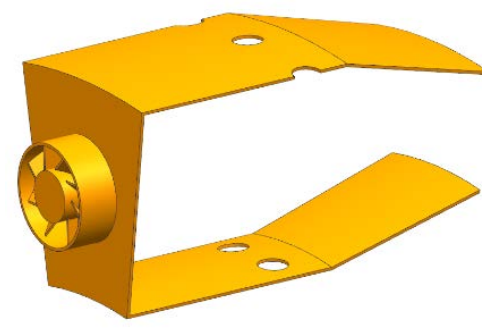

(a) Round holes

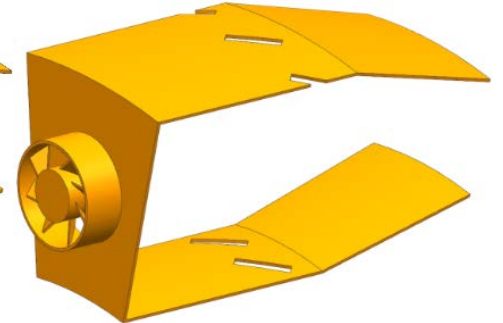

(b) slots with $45^{\circ}$ angle

Fig.2 Quenching unit configurations

\subsection{Computational Grid}

In this study, the commercial CFD code FLUENT has been used to predict the flow and tracer concentration distributions as well as velocity distributions. From the perspective of saving computation cost and enhancing simulation speed, 1/20 sector of the whole combustor is the computational domain with the periodic boundaries. For its complexity, unconstructed grid is employed in the swirler part, while for the large scale chamber, where mainstream flow and quenching flow interact, constructed grid is the best choice, and they are merged on the interface. Moreover, Areas around quenching holes are the places where complex turbulent flow happens, and they are key parts affecting the quenching process, so mesh refinement is conducted here. After verifying the grid indepence, 2 million is the final number of the grid size. The computation grid is showed in fig.3, and boundries types are maked as well. Mainstream and quenching air inlet are all volocity inlets, two sidewalls are taken as periodic boundaries and outlet flow is assumed fully 
developed, and constant pressure at the outlet is considered. All other walls are no-slip and adiabatic walls.

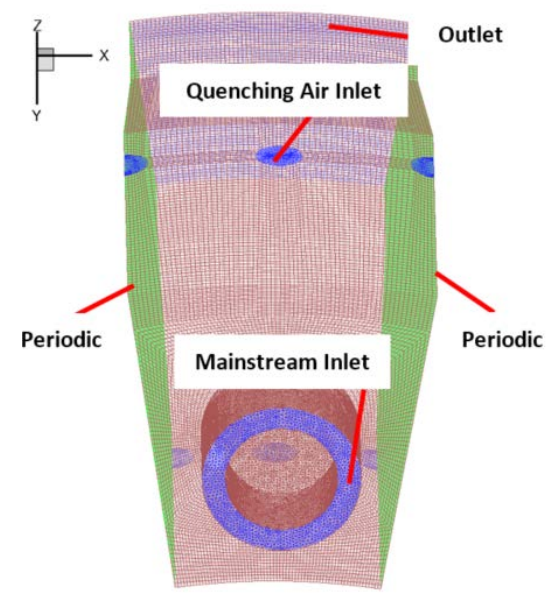

\subsection{Mathematical Models}

Fig.3 Schematic of the computational domain grid

The numerical computations are carried out by solving continuity and momentum equations, shown as Eq.1 and Eq.2.

Continuity-Equation:

$$
\frac{\partial \rho}{\partial t}+\frac{\partial}{\partial x_{j}}\left(\rho u_{j}\right)=0 \quad i, j=1,2,3
$$

Momentum- Equation:

$$
\frac{\partial\left(\rho u_{i}\right)}{\partial t}+\frac{\partial}{\partial x_{j}}\left(\rho u_{i} u_{j}\right)=-\frac{\partial p}{\partial x_{i}}+\frac{\partial}{\partial x_{j}}\left[\rho v\left(\frac{\partial u_{i}}{\partial x_{j}}+\frac{\partial u_{j}}{\partial x_{i}}\right)\right]
$$

The calculations are conducted using the averaged Navier-Stokes equations with Realizable k- $\varepsilon$ turbulence models. The Realizable $\mathrm{k}-\varepsilon$ turbulence model is intended to address deficiencies of traditional k- $\varepsilon$ turbulence model and it is very good at simulating swirling flow, this is why we use it. It's equations are shown in the following:

$$
\begin{aligned}
& \frac{\partial}{\partial t}(\rho k)+\frac{\partial}{\partial x_{i}}\left(\rho k u_{j}\right)=\frac{\partial}{\partial x_{i}}\left[\left(\mu+\frac{\mu_{t}}{\sigma_{k}}\right) \frac{\partial k}{\partial x_{j}}\right]+G_{k}+G_{b}-\rho \varepsilon-Y_{M}+S_{k} \\
& \frac{\partial(\rho \varepsilon)}{\partial t}+\frac{\partial\left(\rho \varepsilon u_{i}\right)}{\partial x_{i}}=\frac{\partial}{\partial x_{j}}\left[\left(\mu+\frac{\mu_{t}}{\sigma_{\varepsilon}}\right) \frac{\partial \varepsilon}{\partial x_{j}}\right]+C_{1 \varepsilon} \frac{\varepsilon}{k} C_{3 \varepsilon} G_{b}-\frac{C_{2} \rho \varepsilon^{2}}{k+\sqrt{v \varepsilon}}+\rho C_{1} S_{\varepsilon}+S_{\varepsilon}
\end{aligned}
$$

where $\mu_{t}=C_{\mu} \rho k^{2} / \varepsilon, G_{k}=-\rho \overline{u_{i}^{\prime} u_{j}^{\prime}} \frac{\partial \overline{u_{j}}}{\partial x_{i}}$.

\subsection{Computation Conditions}

RANS is performed using ANSYS 14.5 Fluent module for operation conditions listed in Table 1. The governing equations re solved numerically by means of SIMPLE algorithm. A second order central-differencing scheme is employed for spatial discretization. Temporal discretization is obtained using a second order implicit scheme and the convergence criterion is that residual of all items lower than $10^{\wedge}-5$.

Table.1 Computation Conditions

\begin{tabular}{rlccc}
\hline $\begin{array}{c}\mathrm{C} \\
\text { ases }\end{array}$ & $\begin{array}{c}\text { Round } \\
\text { holes/ } \\
\text { slots }\end{array}$ & $\begin{array}{c}\text { Mainstream } \\
\text { velocity } \\
\mathrm{V}_{M}(\mathrm{~m} / \mathrm{s})\end{array}$ & $\begin{array}{c}\text { Quenching } \\
\text { velocity } \\
\mathrm{V}_{Q}(\mathrm{~m} / \mathrm{s})\end{array}$ & air \\
\hline 1 & Round holes & 60 & 30 \\
2 & Round holes & 60 & 50 \\
3 & Round holes & 60 & 70 \\
4 & Round holes & 30 & 50 \\
\hline
\end{tabular}


Case1-3 are designed to understand the effect of mainstream velocity on the mixing characteristics, and case 2 and 4 are compared to find the effect of quenching jet velocity. Finally quenching unit configuration effect is examined through comparing Case 2 and 5.

\section{Results and Discussion}

For characterizing the mixing performance, a certain amount of $\mathrm{N}_{2}$ will be added into the quenching jets, changing the $\left[\mathrm{N}_{2}\right]$ mass concentration of the quenching air to 0.87 , while the mainstream is the unchanged air, so the mass concentration $\left[\mathrm{N}_{2}\right]$ keeps 0.77 . It is easy to compare the mixing performance in different cases with the N2 concentration distributions. Besides, mixing non-uniformity $\delta$ is defined to quantize the mixing uniformity, whose expression is shown as follows:

$$
\delta=\frac{1}{n} \sum_{\mathrm{i}=1}^{n}\left(\frac{C_{j}-C_{i}}{C_{j}-C_{\infty}}\right)^{2}
$$

where $C_{j}$ and $C_{\infty}$ is [ $\mathrm{N}_{2}$ ] of the quenching jets and mainstream, respectively, and $C_{i}$ is local [N2] in the mixing plane. Simulation results are mainly presented on the planes shown in Fig4, including one axial-section $(X=0)$ and 6 cross-sections $(Z=125 \mathrm{~mm}, 150 \mathrm{~mm}, 175 \mathrm{~mm}, 200 \mathrm{~mm}, 225 \mathrm{~mm}$ and $250 \mathrm{~mm}$ ), especially , $\mathrm{Z}=125 \mathrm{~mm}$ is the plane where holes center locates.

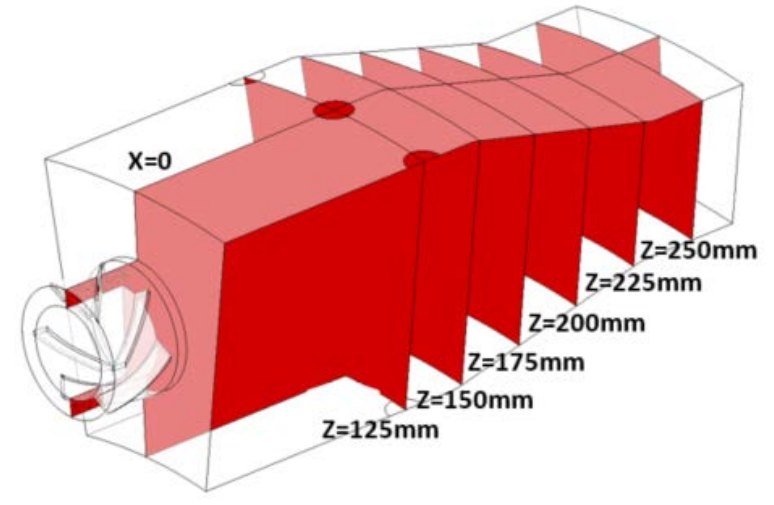

Fig.4 Investigative axial and cross sections

\subsection{Effect of quenching jet velocity}

Fig. 5 shows streamline on the axial section with the quenching jet velocity changing from $30 \mathrm{~m} / \mathrm{s}$ to $70 \mathrm{~m} / \mathrm{s}$, it can be seen from (a) and (b) that, the flow pattern are similar when quenching air velocity increased from $30 \mathrm{~m} / \mathrm{s}$ to $50 \mathrm{~m} / \mathrm{s}$. Two recirculation regions are formed at the outlet of the swirler. But when the velocity increases to $70 \mathrm{~m} / \mathrm{s}$ (c), situation is totally different. Due to the high momentum flux quenching air jetting into the chamber, the rich-burn region flow structure is influenced with one side's recirculation disappearing. Another apparent tendency is that with the augment of $\mathrm{V}_{\mathrm{Q}}$, penetration depth increases.

What is shown in Fig. 6 is N2 concentration distributions on three cross-sections under different quenching air jet velocities, which represents the mixing performance straightly.

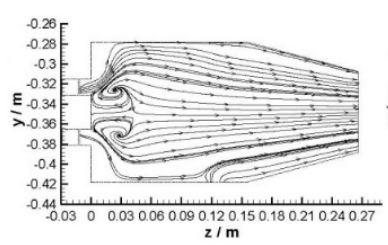

(a) $\mathrm{V}_{Q}=30 \mathrm{~m} / \mathrm{s}$

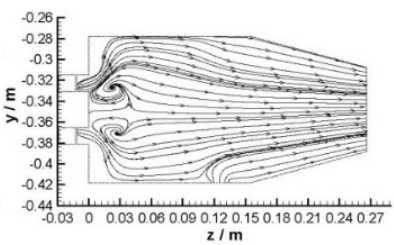

(b) $\mathrm{V}_{Q}=50 \mathrm{~m} / \mathrm{s}$

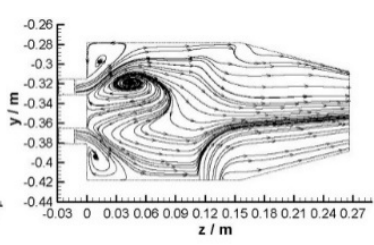

(c) $\mathrm{V}_{Q}=70 \mathrm{~m} / \mathrm{s}$

Fig.5 Streamline on the axial-section $(\mathrm{X}=0)$ for different $\mathrm{V}_{Q}$ 


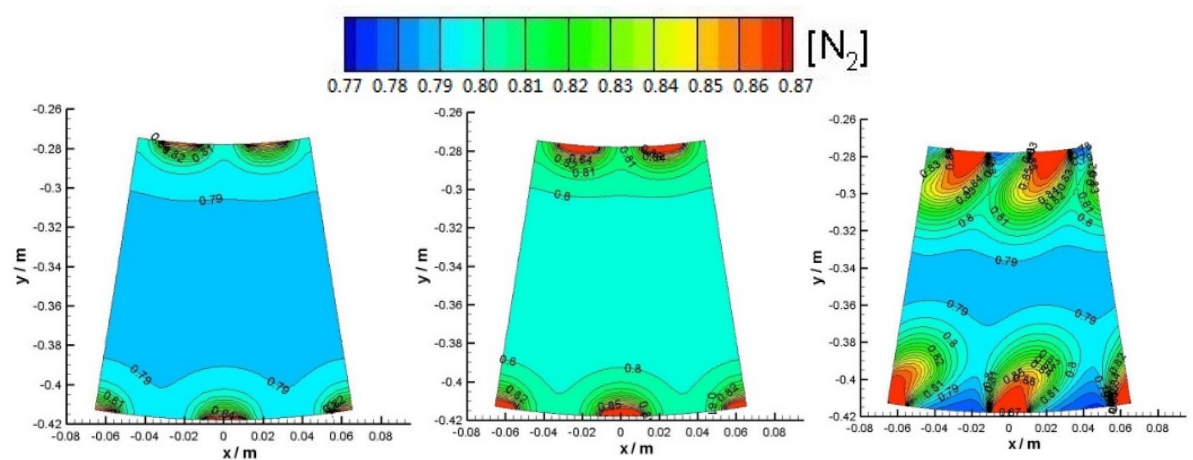

(a) $\mathrm{Z}=125 \mathrm{~mm}, \mathrm{~V}_{Q}=30 \mathrm{~m} / \mathrm{s}(\mathrm{b}) \mathrm{Z}=125 \mathrm{~mm}, \mathrm{~V}_{Q}=50 \mathrm{~m} / \mathrm{s}$ (c) $\mathrm{Z}=125 \mathrm{~mm}, \mathrm{~V}_{Q}=70 \mathrm{~m} / \mathrm{s}$
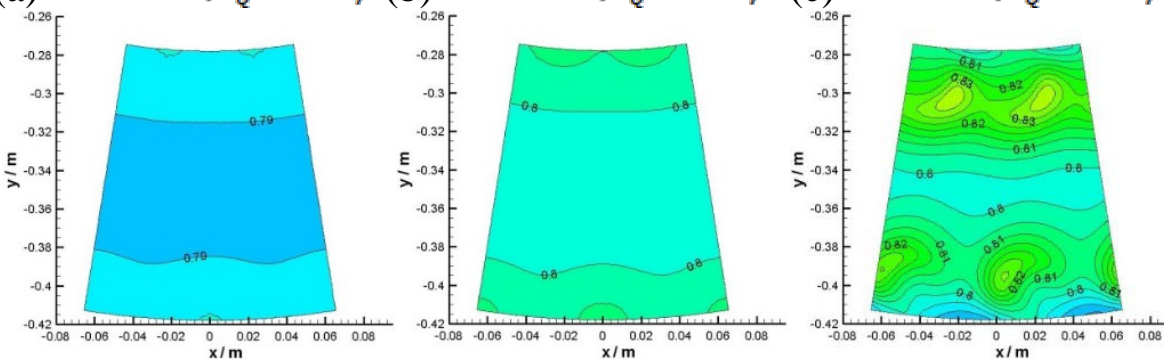

(d) $\mathrm{Z}=150 \mathrm{~mm}, \mathrm{~V}_{Q}=30 \mathrm{~m} / \mathrm{s}$

(e) $\mathrm{Z}=150 \mathrm{~mm}, \mathrm{~V}_{Q}=50 \mathrm{~m} / \mathrm{s}(\mathrm{f}) \mathrm{Z}=150 \mathrm{~mm}, \mathrm{~V}_{Q}=70 \mathrm{~m} / \mathrm{s}$

Fig.6 $\left[\mathrm{N}_{2}\right]$ on the cross-section $(\mathrm{Z}=125 \mathrm{~mm}, 150 \mathrm{~mm})$ for different $\mathrm{V}_{Q}$

It is found that with the quenching air jet velocity increases from $30 \mathrm{~m} / \mathrm{s}$ to $70 \mathrm{~m} / \mathrm{s}$, the variation trend of [N2] distributions on the three planes are similar, which is that the N2 added into the quenching jet will spread to a wider range area with the augment of the quenching air velocity. This also means that the better mixing performance will be obtained at the high quenching velocity cases. Like Fig.7 shows, at the plane $\mathrm{Z}=125 \mathrm{~mm}$, the non-uniformity $\delta$ of $50 \mathrm{~m} / \mathrm{s}$ and $70 \mathrm{~m} / \mathrm{s} \mathrm{V}_{\mathrm{Q}}$ are the same, while $\delta$ increased by $30 \%$ when the quenching air velocity reduced from $50 \mathrm{~m} / \mathrm{s}$ to $30 \mathrm{~m} / \mathrm{s}$. With the development of the flow along stream-wise, the mixing uniformity gets better for the case of $70 \mathrm{~m} / \mathrm{s}$ and finally reaches stable. The opposite trend is happened at the other two low velocities cases. Their non-uniformities become lager along streamwise. Finally, the $\delta$ of $30 \mathrm{~m} / \mathrm{s}$ and $50 \mathrm{~m} / \mathrm{s}$ cases are 1.8 and 1.4 times that of $70 \mathrm{~m} / \mathrm{s}$ case, respectively. The swirling effect is only seen at the $V_{Q}=70 \mathrm{~m} / \mathrm{s}$ case, which corresponds to the momentum flux ratio discussion above.

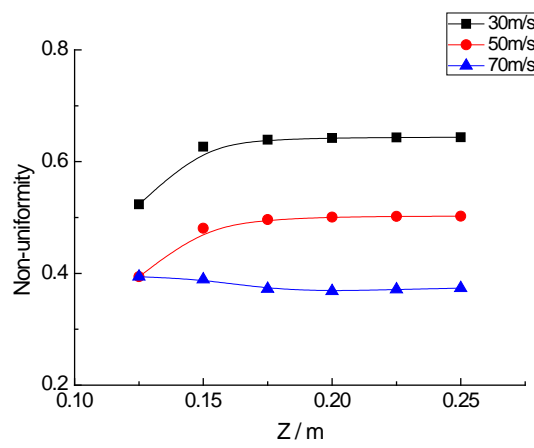

Fig.7 Mixing non-uniformity on cross-sections for different $v_{Q}$

\subsection{Effect of mainstream velocity}

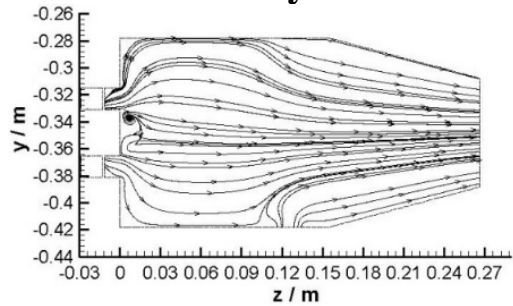

(a) $\mathrm{V}_{M}=30 \mathrm{~m} / \mathrm{s}$

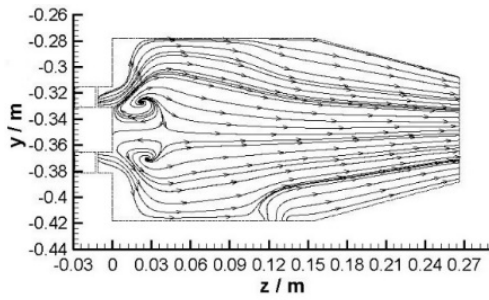

(b) $\mathrm{V}_{M}=60 \mathrm{~m} / \mathrm{s}$ 
Fig.8 Streamline on the axial-section $(\mathrm{X}=0)$ for different $\mathrm{V}_{M}$

Fig.8 shows streamline on the axial section with the mainstream velocity changing from $30 \mathrm{~m} / \mathrm{s}$ to $60 \mathrm{~m} / \mathrm{s}$, while the quenching air velocity keeps $50 \mathrm{~m} / \mathrm{s}$. It can be seen from (a) and (b) that, two recirculation regions of $\mathrm{V}_{\mathrm{M}}=30 \mathrm{~m} / \mathrm{s}$ case diminish (almost disappear) for the low mainstream velocity. In this case, the combustion flame won't be stable. And the quenching penetration of $30 \mathrm{~m} / \mathrm{s}$ mainstream is deeper than that of $60 \mathrm{~m} / \mathrm{s}$ mainstream, as discussed above, which is mainly depended by the momentum flux ratio of quenching air to mainstream.

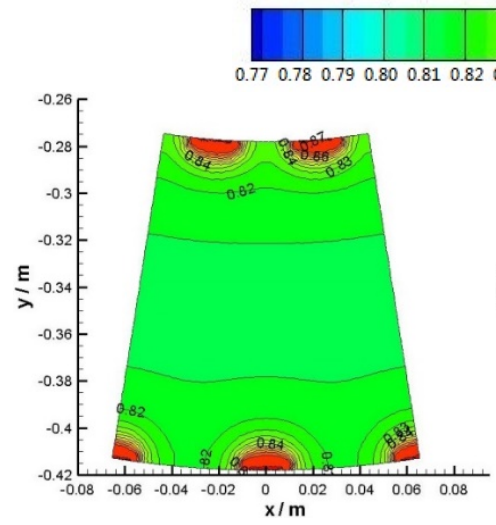

(a) $\mathrm{Z}=125 \mathrm{~mm}, \mathrm{~V}_{M}=30 \mathrm{~m} / \mathrm{s}$

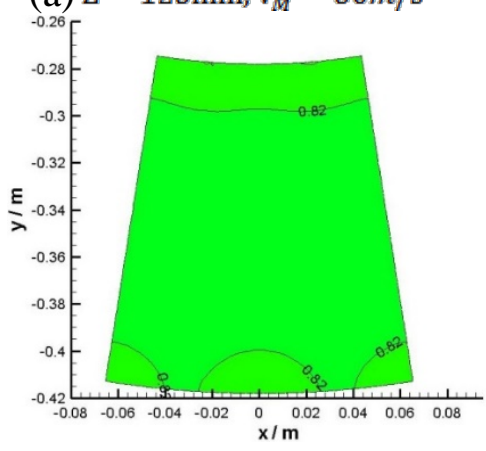

(c) $\mathrm{Z}=150 \mathrm{~mm}, \mathrm{~V}_{M}=30 \mathrm{~m} / \mathrm{s}$

\section{$\left[\mathrm{N}_{2}\right]$}

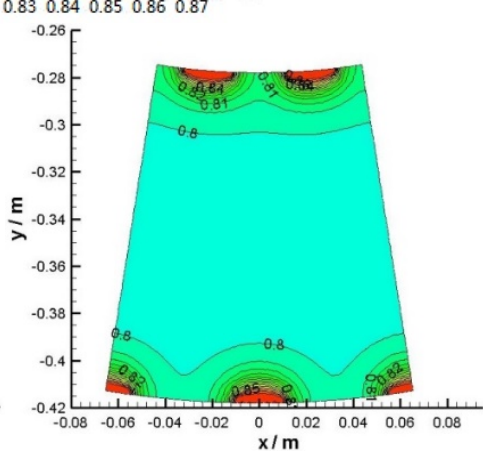

(b) $\mathrm{Z}=125 \mathrm{~mm}, \mathrm{~V}_{M}=60 \mathrm{~m} / \mathrm{s}$

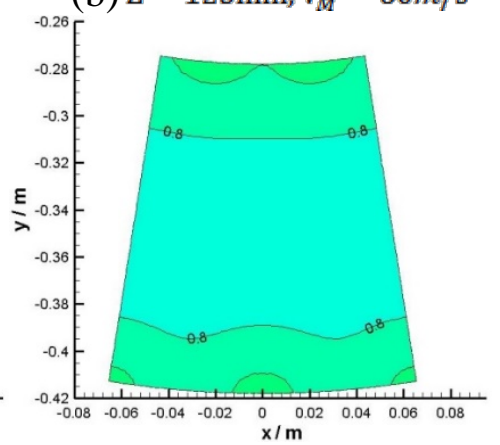

(d) $\mathrm{Z}=150 \mathrm{~mm}, \mathrm{~V}_{M}=60 \mathrm{~m} / \mathrm{s}$

Fig.9 $\left[\mathrm{N}_{2}\right]$ distribution on the cross-section $(\mathrm{Z}=125 \mathrm{~mm}, 150 \mathrm{~mm})$ for different $\mathrm{V}_{M}$

The mixing performance can be seen from the Fig.9 and Fig 10. It is found in Fig.9 that with the mainstream velocity is reduced from $60 \mathrm{~m} / \mathrm{s}$ to $30 \mathrm{~m} / \mathrm{s}$, the $\mathrm{N} 2$ added into the quenching jet will cover a wider range area, which means better mixing performance will be obtained at the low mainstream velocity cases. The non-uniformity result shown in Fig10 confirms the conclusion. At the plane $\mathrm{Z}=125 \mathrm{~mm}$, the non-uniformity $\delta$ increased by $100 \%$ when the mainstream velocity is increased from $30 \mathrm{~m} / \mathrm{s}$ to $60 \mathrm{~m} / \mathrm{s}$. With the development of the flow along stream-wise, the mixing uniformity gets worse for both cases. Finally, $\delta$ of $60 \mathrm{~m} / \mathrm{s}$ case is 2.4 times that of $30 \mathrm{~m} / \mathrm{s}$ case.

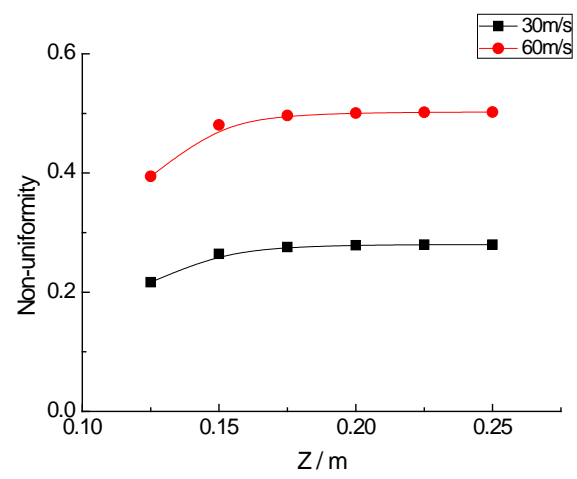

Fig.10 Mixing non-uniformity on cross-sections for different $\mathrm{V}_{Q}$ 


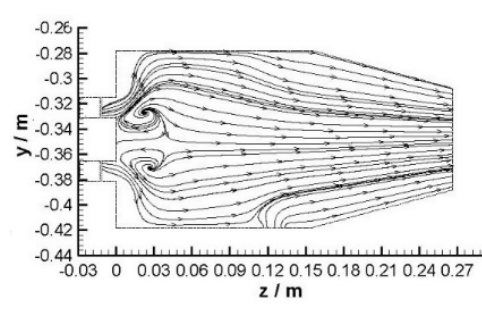

(a) Round holes

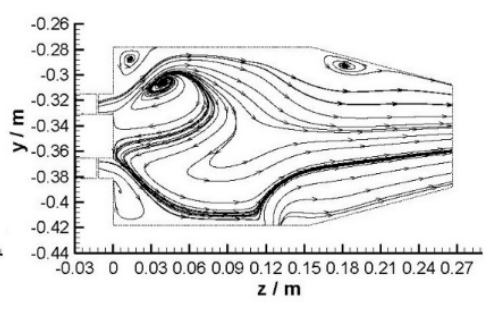

(b) $45^{\circ}$ Slots

Fig.11 Streamline on the axial-section $(\mathrm{X}=0)$ for different configurations

Fig.11 shows streamline on the axial section for two different quenching unit configurations, round holes and $45^{\circ}$ slots. It is found that changing quenching unit configuration will change the flow pattern a lot. When slots are adopted, one side recirculation region is totally destroyed and flow will not be as uniform as the round holes case.

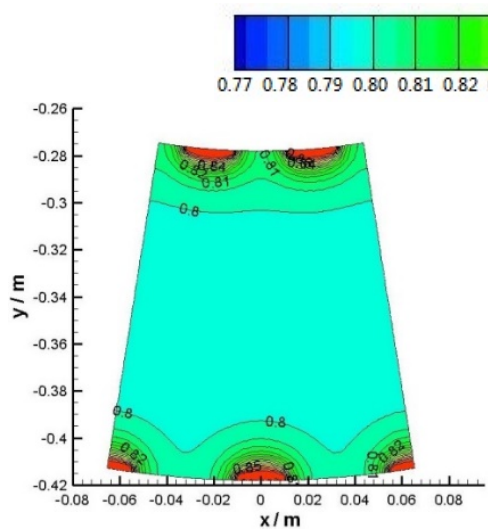

(a) $\mathrm{Z}=125 \mathrm{~mm}$, Round holes

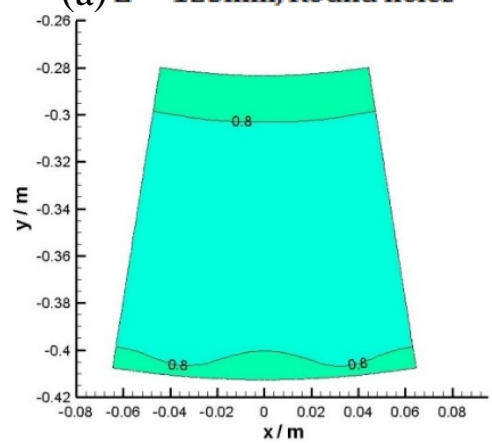

(a) $\mathrm{Z}=150 \mathrm{~mm}$, Round holes

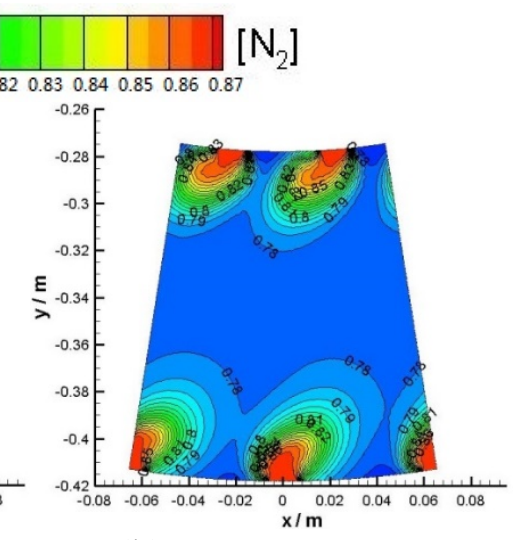

(b) $\mathrm{Z}=125 \mathrm{~mm}, 45^{\circ}$ Slots

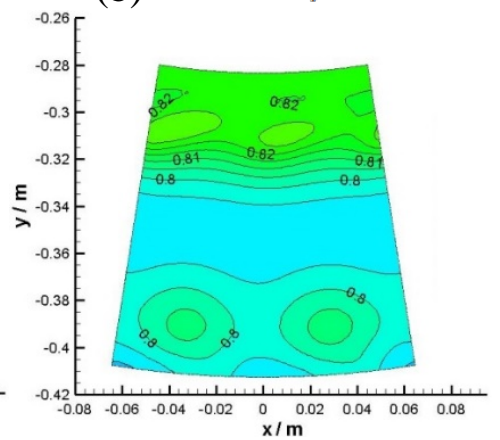

(b) $\mathrm{Z}=150 \mathrm{~mm}, 45^{\circ}$ Slots

Fig.12 $\left[\mathrm{N}_{2}\right]$ distribution on the cross-section $(\mathrm{Z}=125 \mathrm{~mm}, 150 \mathrm{~mm})$ for different quenching unit configurations

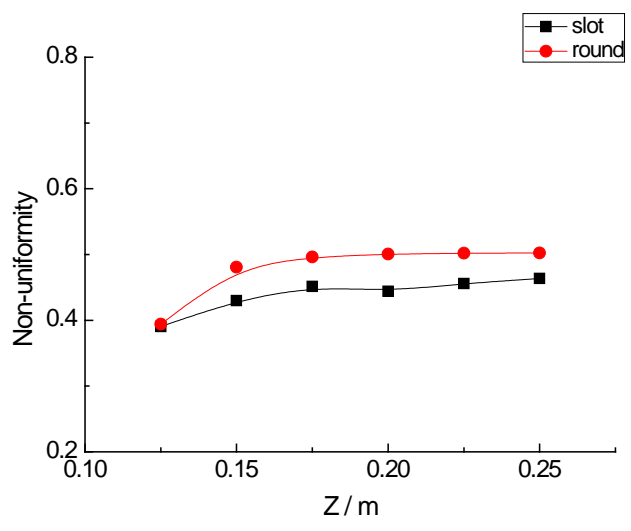

Fig.13 Mixing non-uniformity on cross-sections for different quenching unit configurations 
The mixing performance can be seen from the Fig.12 and Fig 13. It is found in Fig.12 that the N2 added into the quenching jet will spread to cover a wider range when the quenching air is entered through slots, which means better mixing performance will be obtained at the $45^{\circ}$ slots case. The non-uniformity result shown in Fig13 provides more quantification evidence. At the plane $\mathrm{Z}=125 \mathrm{~mm}$, the non-uniformity $\delta$ are almost the same at two cases. With the development of the flow along stream-wise, the mixing uniformity gets worse for both cases. Finally, $\delta$ of the slots case is 1.1 times that of the round holes case. The slots can improve the mixing performance to a small extend.

\section{Conclusions}

A numerical study on mixing characteristics in quenching zone of RQL combustor under the cold flow condition was studied using FLUENT. Three factors including quenching jet velocity, mainstream velocity and quenching unit configuration are considered through comparing flow patterns [N2] distributions as well as mixing un-uniformity. From the results, we can conclude that penetration depth of the quenching jet is mainly determined by the momentum flux ratio of the quenching flow to mainstream flow, bigger ratio will cause deeper penetration. The increase of the quenching jet velocity will improve the mixing uniformity, the mixing un-uniformity $\delta$ of 30m/s and $50 \mathrm{~m} / \mathrm{s}$ cases are 1.8 and 1.4 times that of $70 \mathrm{~m} / \mathrm{s}$ case, respectively. Besides, better mixing performance will be obtained at the low mainstream velocity cases, $\delta$ of $60 \mathrm{~m} / \mathrm{s}$ case is 2.4 times that of $30 \mathrm{~m} / \mathrm{s}$ case. Finally, the quenching unit configuration can influence the flow pattern a lot and the $45^{\circ}$ slots case shows better mixing performance than the round holes case, but the effect is limited.

Acknowledgments The present research was supported by Aeronautical Science Foundation of China (No. 2012ZBN2011).

\section{References}

[1] Mosier S A, Pierce R M. Advanced combustor systems for stationary gas turbine engines, phase I : Review and preliminary evaluation [R]. U.S. Environmental Protection Agency, 1980.

[2] Samuelsen S. The gas turbine handbook [M]. U.S. Department of Energy, Office of Fossil Energy, National Energy Technology Laboratory, 2006.

[3] Oechsle V L, Mongia H C. Comparison of mixing calculations for reacting and non-reacting flows in a cylindrical duct [R]. AIAA-94-0865, 1994.

[4] Leong M Y, Samuelsen G S. Optimization of jet mixing into a rich, reacting crossflow [J]. Journal of Propulsion and Power, 2000,15(5).

[5] Leong M Y, Samuelsen G S. Jet mixing in a reacting cylindrical crossflow [R]. AIAA-95-3, 1995.

[6] Zhu G. Penetration and mixing of radial jets in neck-down cylindrical crossflow [J]. Journal of Propulsion and Power. 1995,11(2).

[7] Zhu G, Lai M C. A parametric study of penetration and mixing of radial jets in necked-down cylindrical crossflow [R]. AIAA 92-309, 1992.

[8] Blomeyer M. Mixing zone optimization of a Rich-Burn /Quick-Mix/ Lean-Burn combustor [J]. Journal of Propulsion and Power. 1999,15(2).

[9] Howe G W. Simulation of mixing in the quick quench region of a rich burn-quick quench mix-lean burn combustor [R]. 29th Aerospace Sciences Meeting, 1991.

[10] Smlth C E, Talpalllkar M V. A CFD study of jet mixing in reduced flow areas for lower combustor emissions [R]. AIAA-91-2460, 1991. 